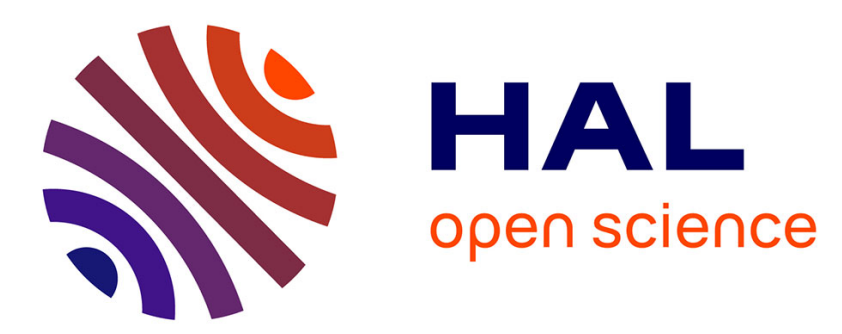

\title{
Single-walled carbon nanotubes modified by ionic liquid as antiwear additives of thermoplastics
}

\author{
F.J. Carrión, C. Espejo, J. Sanes, M.D. Bermúdez
}

\section{To cite this version:}

F.J. Carrión, C. Espejo, J. Sanes, M.D. Bermúdez. Single-walled carbon nanotubes modified by ionic liquid as antiwear additives of thermoplastics. Composites Science and Technology, 2010, 70 (15), pp.2160. 10.1016/j.compscitech.2010.08.018 . hal-00690069

\section{HAL Id: hal-00690069 \\ https://hal.science/hal-00690069}

Submitted on 21 Apr 2012

HAL is a multi-disciplinary open access archive for the deposit and dissemination of scientific research documents, whether they are published or not. The documents may come from teaching and research institutions in France or abroad, or from public or private research centers.
L'archive ouverte pluridisciplinaire HAL, est destinée au dépôt et à la diffusion de documents scientifiques de niveau recherche, publiés ou non, émanant des établissements d'enseignement et de recherche français ou étrangers, des laboratoires publics ou privés. 


\section{Accepted Manuscript}

Single-walled carbon nanotubes modified by ionic liquid as antiwear additives of thermoplastics

F.J. Carrión, C. Espejo, J. Sanes, M.D. Bermúdez

PII:

S0266-3538(10)00341-6

DOI:

10.1016/j.compscitech.2010.08.018

Reference:

CSTE 4799

To appear in:

Composites Science and Technology

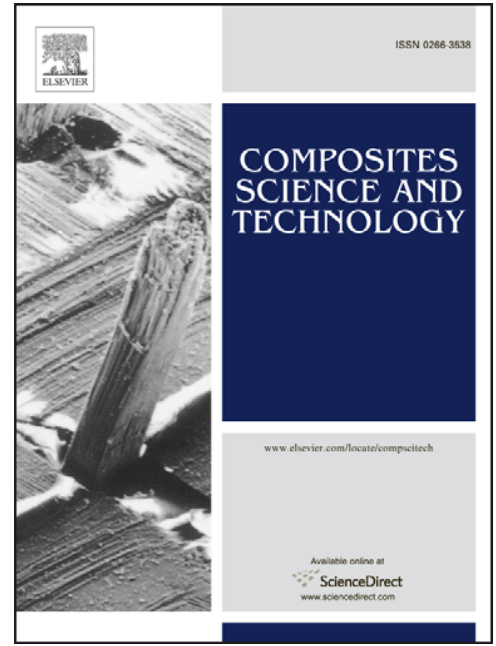

Received Date: $\quad 9$ August 2010

Revised Date: $\quad 23$ August 2010

Accepted Date: $\quad 26$ August 2010

Please cite this article as: Carrión, F.J., Espejo, C., Sanes, J., Bermúdez, M.D., Single-walled carbon nanotubes modified by ionic liquid as antiwear additives of thermoplastics, Composites Science and Technology (2010), doi: 10.1016/j.compscitech.2010.08.018

This is a PDF file of an unedited manuscript that has been accepted for publication. As a service to our customers we are providing this early version of the manuscript. The manuscript will undergo copyediting, typesetting, and review of the resulting proof before it is published in its final form. Please note that during the production process errors may be discovered which could affect the content, and all legal disclaimers that apply to the journal pertain. 


\title{
Single-walled carbon nanotubes modified by ionic liquid as antiwear additives of thermoplastics
}

\author{
F. J. Carrión, C. Espejo, J. Sanes, M.D. Bermúdez \\ Grupo de Ciencia de Materiales e Ingeniería Metalúrgica. Departamento de Ingeniería \\ de Materiales y Fabricación. Universidad Politécnica de Cartagena. \\ Campus de la Muralla del Mar. C/Doctor Fleming, s/n. 30202-Cartagena (Spain)
}

\begin{abstract}
Pristine single-walled carbon nanotubes (CNTs) were dispersed in the roomtemperature ionic liquid (IL) 1-octyl, 3-methylimidazolium tetrafluoroborate $\left([\mathrm{OMIM}] \mathrm{BF}_{4}\right)$ by grinding and ultrasounds. Excess IL was removed to obtain singlewalled carbon nanotubes modified by $\left[\mathrm{OMIM}_{\mathrm{BF}}\right.$ (mCNTs). mCNTs were added in a 1wt.\% to polystyrene (PS), polymethylmethacrylate (PMMA) and polycarbonate (PC) to obtain PS+mCNT, PMMA+mCNT and PC+mCNT. The dry tribological performance of the new nanocomposites was studied against AISI 316L stainless steel pins and compared with that of the neat polymers and with the nanocomposites containing pristine carbon nanotubes without IL (PS+CNT; PMMA+CNT and $\mathrm{PC}+\mathrm{CNT})$. The maximum wear rate and friction coefficient reduction is obtained for PS+mCNT. Results are discussed upon the basis of optical, SEM and TEM microscopy, thermogravimetric analysis (TGA), Raman spectroscopy, X-ray diffraction (XRD) and X-ray photoelectron spectroscopy (XPS).
\end{abstract}

Keywords: A. Polymers; A. Ionic liquids; A. Carbon nanotubes; A. Nanocomposites; B. Friction/wear. 


\section{Introduction}

Tribology of polymers and polymer-matrix composites is increasingly relevant due to their growing applications in sliding parts, as surface finishing materials and in selflubricating components [1]. Most applications require dry conditions to avoid polymer degradation and contamination by oils or greases, and to reduce maintenance. There exists a growing interest in the development of polymer nanocomposites with enhanced tribological performance [2-7].

From the first report [8], nanotube-polymer composites have been intensively studied [9-12]. Most studies are referred to their electrical and mechanical properties [13].

Chemical functionalization usually improves the dispersion and interactions with the matrix and increases mechanical resistance $[14,15]$. Studies on the tribological behaviour of carbon nanotubes-reinforced composites are still relatively scarce [16-20] and, in many cases, have led to contradictory results [21]. Some studies have found that the addition of carbon nanotubes to polymer matrices reduces the friction coefficient and wear rate of the polymer, but others showed that the composites tribological performance was not improved by the use of carbon nanotube additives. Room temperature ionic liquids have shown promising lubricating performance for metals and ceramic materials under severe conditions [22-26]. The combination of ionic liquids and nanophases has given rise to new nanofluids with promising applications [27]. In

particular, the ability of ionic liquids to disperse and chemically modify carbon nanotubes has raised great interest [28-31]. Imidazolium ion-based room-temperature ILs grounded with pristine single-walled carbon nanotubes (CNTs) form gels by physical cross-linking of the nanotube bundles, mediated by local molecular ordering of the ionic liquids. The overall organization of ionic liquids is not remarkably altered by single-walled carbon nanotubes. However, ionic liquids disperse the CNTs by shielding 
the stacking interaction among them. The ionic liquids interact with CNTs through weak van der Waals interaction without influence on their electronic structure and properties [28-31].

Multi-walled carbon nanotubes chemically modified by an ionic liquid have been recently used as additives of ionic liquid lubricants in steel-steel contact [32, 33]. In recent studies, we have shown that it is possible to improve the tribological performance of thermoplastics [34-39] and of epoxy resin [40] against steel by preparing new

dispersions containing variable concentrations of ILs or IL-modified ZnO nanoparticles. We have recently described [41] that single-walled carbon nanotubes (CNTs) dispersed in 1-octyl, 3-methylimidazolium chloride ([OMIM]Cl) can be used as external lubricant of PC/stainless steel contact. However, as many applications require dry sliding, in the present work new polystyrene (PS), polymethylmethacrylate (PMMA) and polycarbonate (PC) nanocomposites have been obtained by adding IL-modified singlewalled carbon nanotubes to the polymer matrices.

The IL selected was 1-octyl, 3-methylimidazolium tetrafluoroborate ([OMIM]BF 4$)$ due to its good performance as metal-metal lubricant [22-26] and as lubricant or additive of epoxy resin nanocomposites [39]. The main purpose of the present study is to determine the influence of IL on the dry friction and wear of polymer nanocomposites containing single-walled carbon nanotubes.

\section{Experimental}

Single-walled carbon nanotubes (CNTs) (1-2 nm diameter; 5-30 $\mu \mathrm{m}$ length) (NanoAmor Inc.) obtained by the catalytic Chemical Vapour Deposition method, with $>90 \%$ content in single-walled carbon nanotubes $(96,30 \% \mathrm{C} ; 0,08 \% \mathrm{Al} ; 0,41 \% \mathrm{Cl} ; 2.91 \% \mathrm{Co} ; 0.29 \%$ S), were used as-received. 1-octyl, 3-methylimidazolium tetrafluoroborate [OMIM]BF 4 (Fluka, Germany) with $>98 \%$ purity was used as received. CNTs were mixed with the 
$\mathrm{IL}[\mathrm{OMIM}] \mathrm{BF}_{4}$ in a $0.5 \mathrm{wt} . \%$ proportion, grinded in an agate mortar for about 5-10 minutes and ultrasonicated for 30 minutes in an ultrasonic bath, following a procedure similar to that first described by Fukushima et al. [28]. To obtain IL-modified singlewalled carbon nanotubes (mCNT), excess IL was removed and the residue was washed with acetonitrile and dried in an oven under vacuum at $70^{\circ} \mathrm{C}$ during 24 hours. The thermoplastics used were polymethylmethacrylate (PMMA) (Buehler), polystyrene (PS) (Aldrich) and polycarbonate (PC) (LS2, Sabic Innovative Plastics). The nanocomposites were obtained by milling the polymers with a $1 \mathrm{wt} . \%$ proportion of CNT or mCNT in an Retsch ZM200 ultracentrifugal mill at 18,000 rpm. The powders were then compression moulded in a Hitech Europe EP15 press $\left(0.4 \mathrm{MPa}\right.$ at $175^{\circ} \mathrm{C}$ for PS and PMMA; $0.5 \mathrm{MPa}$ at $200^{\circ} \mathrm{C}$ for PC). A Differential scanning calorimeter (DSC) $822 \mathrm{e}$ (Mettler-Toledo) was used to determine glass transition temperatures $\left(\mathrm{T}_{\mathrm{g}}\right) .15 \mathrm{mg}$ samples were heated under an inert $\mathrm{N}_{2}$ atmosphere $(50 \mathrm{ml} / \mathrm{min})$, at a heating rate of $10^{\circ} \mathrm{C} / \mathrm{min}$. Decomposition temperatures $\left(T_{d}\right)$ were determined in air with a Shimadzu thermogravimetric analyzer (TGA)-50 equipment $\left(20^{\circ} \mathrm{C} / \mathrm{min} ; \mathrm{N}_{2}, 40 \mathrm{ml} / \mathrm{min}\right)$. Raman spectra were collected using a Nicolet Almega XR Raman spectrometer from Thermo Electron, equipped with an Olympus microscope and a motorized stage for higher accuracy. A laser of $780 \mathrm{~nm}$ at $100 \%$ of power and $50 \mu \mathrm{m}$ of aperture was used. Raman maps were recorded along a line of $250 \mu \mathrm{m}$, in the range between 150 and $2800 \mathrm{~cm}^{-1}$, where each spectrum was collected every $5 \mu \mathrm{m}$, with a total of 50 spectra.

Pin-on-disc tests were carried out in a Microtest tribometer using polymer discs (diameter $40 \mathrm{~mm}$; thickness $4 \mathrm{~mm}$ ) against AISI 316L stainless steel pins with a $0.8 \mathrm{~mm}$ tip sphere radius, with a hardness of $210 \mathrm{HV}$. Normal applied load was $0.49 \mathrm{~N}$ (mean contact pressure $0.07 \mathrm{GPa}$ ), sliding velocity $0.10 \mathrm{~ms}^{-1}$, sliding distance $500 \mathrm{~m}$ and sliding radius $9 \mathrm{~mm}$. At least three tests, with standard deviations lower than 5\%, were 
performed under the same experimental conditions for each material. Wear tracks were observed by optical microscopy (Leica DMRX) and image analysis (OPTIMAS 6.2). SEM images were obtained using a Hitachi S3500N. The samples were gold coated with a SC7640 Sputter Coater before observation. Transmission electron microscopy (TEM) micrographs were obtained with a high resolution JEOL JEM 2100. X-ray photoelectron (XPS) spectra were obtained using a VG-Microtech Multilab 3000. The binding energies were referenced to the $\mathrm{C} 1 \mathrm{~s}$ peak $(284.6 \mathrm{eV})$ used as internal standard. The precision in the binding energy is estimated to be \pm 0.1 . X-ray diffraction patterns were recorded in a Bruker D-8 Advance diffractometer using a wavelength of $1.542 \AA$ from $\mathrm{Cu}-\mathrm{K} \alpha$, with an angular speed of $120 \mathrm{~s} /$ degree at room temperature.

\section{Results and discussion}

\subsection{TEM microscopy}

Pristine single-walled carbon nanotubes (CNTs) (figure 1a) contain a mixture of carbon nanostructures, bundles, catalyst residues and other impurities as can be seen in the TEM micrograph (figure 1a) and by the chemical analysis (see Experimental). mCNT show a similar morphology (figure 1b) to that of pristine CNT, although treatment with $[\mathrm{OMIM}] \mathrm{BF}_{4}$ affords some nanotube disentanglement. Figures $1 \mathrm{c}-1 \mathrm{e}$ show TEM micrographs of mCNT in the polymer matrices. Some individual mCNT can be observed within the matrix of PS (figure 1c), but also some zones free from mCNT.

The compression moulding processing used to prepare the nanocomposites give no preferential orientation of the nanotubes within the polymer matrices.

\subsection{Thermal properties}

Pristine CNT show a weight loss of a $7 \%$ at $800^{\circ} \mathrm{C}$, while neat IL presents an onset temperature for thermal degradation of $427^{\circ} \mathrm{C}$. 
An estimation of the IL proportion present in dry mCNT has been made from TGA results, which presents an onset temperature for thermal degradation at $364.8^{\circ} \mathrm{C}$, with a total weight loss of $52.4 \%$ from room temperature to $600^{\circ} \mathrm{C}$. This weight loss should correspond to the IL content in mCNT, together with some water and other impurities, present either in the IL or in the CNT.

Table 1 shows glass transition temperatures $\left(T_{g}\right)$ and degradation temperatures $\left(T_{d}\right)$ for neat polymers, and nanocomposites. The influence of the additives on the thermal properties of the nanocomposites is different for each material. $T_{g}$ values for PS and PS nanocomposites are very similar, while degradation temperatures are increased by the addition of CNT or mCNT. The higher thermal stability of PS+mCNT could increase the tribological performance of this nanocomposite. In the case of PMMA, the thermal stability of the nanocomposites is lower than that of the neat polymer, while $T_{g}$ values increase. The most significant $\mathrm{T}_{\mathrm{g}}$ increase $\left(+5.4^{\circ} \mathrm{C}\right)$ takes place when $\mathrm{mCNTs}$ are added. Only PC shows a reduction both of $\mathrm{T}_{\mathrm{g}}$ and $\mathrm{T}_{\mathrm{d}}$ with the addition of CNTs and a further reduction of the thermal stability with the addition of mCNTs.

\subsection{Raman spectroscopy}

Both pristine CNTs and IL-modified nanotubes (mCNT) show the characteristic G band at $1584 \mathrm{~cm}^{-1}$, assigned to the in-plane vibrations of the graphitic wall, and D band at $1303 \mathrm{~cm}^{-1}$ originating from disorder in the graphitic structure. The $\mathrm{D} / \mathrm{G}$ intensity ratio is used as an indicator of the degree of crystallinity and purity of the carbon nanotubes [42]. When both bands have similar intensity, it is indicative of a high proportion of structural defects. A lower D/G intensity ratio indicates a higher crystallinity. The D/G intensity ratios for $\mathrm{CNT}, \mathrm{mCNT}$ and for the three polymer+mCNT nanocomposites are compared in table 2 . mCNT shows a $7 \%$ decrease in the $\mathrm{D} / \mathrm{G}$ intensity ratio with respect to pristine CNT. This would be in agreement with the surface modification of CNT 
surface by the IL molecules. A further decrease in the D/G intensity ratio is observed when mCNT are added to polymer matrices. At the same time, the interaction with polymer matrices produces a displacement of the D and G band Raman shift of the nanocomposites to higher wavenumbers with respect to CNT and mCNT. Figures 2a, 3a and $4 \mathrm{a}$ show the $250 \mu \mathrm{m}$ lines along the cross sections of PS+mCNT, PMMA+mCNT and $\mathrm{PC}+\mathrm{mCNT}$, respectively. The scan-line Raman maps are shown in figures $2 \mathrm{~b}, 3 \mathrm{~b}$ and $4 \mathrm{~b}$, and the variations of the intensities of the $G$ and $D$ bands along the line are shown in figures $2 \mathrm{c}, 3 \mathrm{c}$ and $4 \mathrm{c}$. PS and PMMA show a more uniform dispersion of mCNT (figures 2a and 3a, respectively) than PC (figure 4a). The intensities of the D and $\mathrm{G}$ bands are also more uniform along the scan line for PS (figure 2c) and PMMA (figure 3c) than for PC (figure 4c). This confirms that, under the experimental conditions described here, a less uniform dispersion has been obtained in the case of PC.

\subsection{XRD}

Figure 5 shows the XRD patterns obtained for neat $[\mathrm{OMIM}] \mathrm{BF}_{4}$ (figure $5 \mathrm{a}$ ), for asreceived single-walled carbon nanotubes (CNT) (figure 5b) and after treatment with $[\mathrm{OMIM}] \mathrm{BF}_{4}(\mathrm{mCNT}$; figure $5 \mathrm{c})$. The neat IL shows a broad intense diffraction peak at $2 \theta=20.34^{\circ}$, corresponding to a d spacing of $4.38 \AA$, in accordance with an arrangement of molecules IL in the liquid state. CNT (figure 5b) show a characteristic peak at $2 \theta=$ $25.75^{\circ}$, with a spacing of $3.47 \AA$, corresponding to graphite layers. The main diffraction peak observed for mCNT (figure 5c), assigned to the IL-modified carbon nanotubes appears at $3.53 \AA$, but lower intensity peaks are also observed at 4.71, 5.28, 6.33 and $8.26 \AA$, which could correspond to IL molecules stacked on the nanotubes surface, as previously described [23, 24].

\subsection{XPS analysis}


The surface modification of the carbon nanotubes by the IL has been confirmed by the shift of the $\mathrm{C} 1 \mathrm{~s}$ binding energies from 284.2 and $285.6 \mathrm{eV}$ in pristine CNTs

(corresponding to $\mathrm{sp}^{2} \mathrm{C}=\mathrm{C}$ and $\mathrm{sp}^{3} \mathrm{C}-\mathrm{C}$ ), to 284.4 and $286.1 \mathrm{eV}$ in $\mathrm{mCNT}$, and by the presence of a peak at a binding energy of $402.1 \mathrm{eV}$, corresponding to $\mathrm{N} 1 \mathrm{~s}$ in the XPS spectrum of mCNT. F1s and $\mathrm{B} 1 \mathrm{~s}$ binding energies due to the $\mathrm{BF}_{4}{ }^{-}$anion were too weak to be assigned.

\subsection{Tribological performance and wear mechanisms}

In agreement with previous results on friction coefficients of polymer-steel contacts under severe sliding conditions, friction coefficients against AISI 316L pins (table 3) are very high, with values around 1, both for neat polymers and polymers+mCNTs. Addition of the IL-modified nanotubes only decrease significantly (in a 19\%) the friction coefficient in the case of PS, which is the polymer that also shows a higher wear decrease (figure 6a), with reduction of wear debris in the polymer-steel interface (figure 7).

Specific wear rates (figure 6a) for all dispersions are lower than those of the base polymers. In all cases the nanocomposites containing single-walled carbon nanotubes previously treated with $[\mathrm{OMIM}] \mathrm{BF}_{4}(\mathrm{mCNTs})$ show the best tribological performance. The highest wear rate reduction is observed for the brittle polystyrene [6]. Addition of CNTs reduces the wear rate of PS in a $24 \%$, but the reduction reaches a $74 \%$ (with respect to neat PS) and a 65\% (with respect to PS+CNT) when mCNTs are added. The influence of mCNT reinforcement in PS is shown in figure $6 \mathrm{~b}$, which shows the fracture surface of PS $+\mathrm{mCNT}$, with the presence of carbon nanotube bundles bridging the gap through the crack opening [4].

A significative reduction is also observed for PMMA+mCNT which presents a wear rate decrease of a $58 \%$ with respect to $\mathrm{PMMA}+\mathrm{CNT}$, and a $63 \%$ reduction with respect 
to neat PMMA. The wear rate of neat PC is reduced by $8 \%$ by the addition of CNT and by $14 \%$, with respect to neat $\mathrm{PC}$, when $\mathrm{mCNT}$ s are added $(6.4 \%$ reduction with respect to PC+CNT). These results confirm the effective antiwear effect of the IL. Figure 7 compares the wear tracks and wear derbris of PS (figure 7a), PMMA (figure 7c), PC (figure 7e) and of the nanocomposites (PS+mCNT, figure 7b; PMMA+mCNT, figure 7d; PC+mCNT, figure 7f). The severe wear with massive wear debris removal observed for neat PS (figure 7a) is substituted for PS $+\mathrm{mCNT}$ by a milder wear regime with formation of a tribolayer on the wear track, and reduction of the quantity and size of wear debris (figure 7b). PMMA (figure 7c) and PMMA+mCNT (figure 7d) show more similar wear mechanisms, but in the case of PMMA+mCNT, the damage produced by the steel pin is limited to the surface layers, thus reducing the wear rate. Only PC (figure 7e) and PC+mCNT (figure 7f) show very similar wear mechanisms, with severe wear and wear debris removal outside the wear track. The less effective reinforcement observed for PC nanocomposites with respect to those of PS and PMMA can be attributed to a less uniform dispersion of the additive in the PC matrix as we have seen in the Raman spectroscopy study.

\section{Conclusions}

New PS, PMMA and PC nanocomposites containing single-walled carbon nanotubes modified by the ionic liquid $\left[\mathrm{OMIM}_{\mathrm{B}} \mathrm{BF}_{4}(\mathrm{mCNTs})\right.$ have been obtained and their tribological behaviour compared with that of neat polymers and nanocomposites containing pristine single-walled carbon nanotubes (CNTs). The most significant friction coefficient reduction is observed in the case of PS+mCNT. Wear rates are reduced in all cases, with the maximum reduction found for polymer+mCNT nanocopmsites. The best tribological performance is found for PS+mCNT and 
PMMA+mCNT, with a wear rate reduction with respect to the neat polymers of $74 \%$ and $63 \%$, and of a $65 \%$ and $60 \%$ with respect to PS+CNT and PMMA+CNT, respectively. This wear reduction is attributed to the dispersion of the nanotubes in the polymer matrix, which increases their resistance to crack propagation and fracture, and to the surface modification of the nanotubes by the ionic liquid, which improves the lubricating ability of the additive. The less uniform dispersion observed for PC would be responsible for its poorer performance.

\section{Acknowledgements}

The authors wish to thank the financial support of MICINN (España), the european FEDER program (MAT2008-01670), and the "Programa de Generación de

Conocimiento Científico de Excelencia” Fundación Séneca (08596/PI/08).

\section{References}

1. Burris DL, Boes1 B, Bourne GR, Sawyer WG. Polymeric materials for tribological applications. Macromol Mater Eng 2007;292:387-402.

2. Brostow W, Deborde JL, Jacklevicz M, Olszynski P. Tribology with emphasis on polymers: friction, scratch resistance and wear. J Mater Ed 2003;25:119-132.

3. Myshkin M, Petrokovets MI, Kovalev AV. Tribology of polymers: friction, wear and mass transfer. Tribol Int 2005;38:910-921.

4. Brostow W, Simoes R. Tribological and mechanical behaviour of polymers simulated by molecular dynamics. J Mater Ed 2005; 27:19-28.

5. Kopczynska A, Ehrenstein GW. Polymeric surfaces and their true surface tension in solids and melts. J Mater Ed 2007;29:325-340.

6. Brostow W, Hagg HE, Narkis M. Sliding wear, viscoelasticity and brittleness of polymers. J Mater Res 2006;21:2422-2428. 
7. Dasari A, Yu ZZ, Mai YW. Fundamental aspects and recent progress on wear/scratch damage in polymer nanocomposites. Mater Sci Eng: R 2009;63:31-80.

8. Ajayan PM, Stephan O, Colliex C, Trauth D. Aligned carbon nanotubes arrays formed by cutting a polymer resin nanotube composite. Science 1994;265:1212-1214. 9. Ajayan PM, Chadler LS, Giannaris C, Rubio A. Single-walled carbon nanotubepolymer composites: strength and weakness. Adv Mater 2000;12:750-753.

10. Thostenson ET, Ren Z, Chou TW. Advances in the science and technology of carbon nanotubes and their composites: a review. Compos Sci Technol 2001;61:1899_ 1912.

11. Xie XL, Mai YW, Zhou XP. Dispersion and alignment of carbon nanotubes in polymer

matrix: A review. Mater Sci Eng R 2005; 49:89-112.

12. Moniruzzaman, M Winey, KI. Polymer nanocomposites containing carbon nanotubes Macromolecules 2006;39:5194-5205.

13. Spitalsky Z, Tasis D, Papagelis K, Galiotis C. Carbon nanotube-polymer composites: Chemistry, processing, mechanical and electrical properties. Prog Polym Sci $2010 ; 35: 357-401$.

14. Ramanathan T, Liu H, Brinson LC. Functionalized SWNT/polymer nanocomposites for dramatic property improvement. J Polym Sci Part B: Polym Phys 2005;43:22692279.

15. Zheng Y, Zhang J, Xiaodong Y, Chen W, Wang R. Effects of Functionalized MWNTs with GMA on the Properties of PMMA Nanocomposites. J Appl Polym Sci 2009;112:1755-1761. 
16. Dong B, Yang Z, Huang Y, Li HL. Preparation and tribological properties of poly(methyl methacrylate)/styrene/MWNTs copolymer nanocomposites Tribol Lett $2005 ; 20: 251-254$.

17. Cho MH, Bahadur S. A study of the thermal, dynamic mechanical, and tribological properties of polyphenylene sulfide composites reinforced with carbon nanofibers Tribol Lett 2007;25:237-245.

18. Cai H, Yan, FY Xue, QJ. Investigation of tribological properties of polyimide/carbon nanotube nanocomposites. Mater Sci Eng A-Struct Mater Prop Microstruct Process 2004;364:94-100.

19. Dong B, Wang C, He BL, Li HL. Preparation and tribological properties of poly(methyl methacrylate)/styrene/MWNTs copolymer nanocomposites. J Appl Polym Sci. 2008;108:1675-1679.

20. Giraldo LF, Brostow W, Devaux E, Lopez BL, Perez LD, Scratch and wear resistance of polyamide 6 reinforced with multiwall carbon nanotubes. J Nanosci Nanotechnol 2008;8: 3176-3183.

21. Mylvaganam K, Zhang LZ, Xiao KQ. Origin of friction in films of horizontally oriented carbon nanotubes sliding against diamond. Carbon 2009;47:1693-1700.

22. Torimoto T, Tsuda T, Okazaki K, Kuwawata, S. New frontiers in materials science opened by ionic liquid. Adv Mater 2010;22:1196-1221.

23. Minami I. Ionic liquids in tribology. Molecules 2009;14:2262-2269.

24. Zhou F, Liang Y, Liu W. Ionic liquid lubricants: designed chemistry for engineering applications. Chem Soc Rev 2009;28:2590-2599.

25. Bermúdez MD, Jiménez AE, Sanes J, Carrión FJ. Ionic liquids as advanced lubricants. Molecules 2009;14:2888-2908. 
26. M. Palacio, B. Bhushan, A Review of Ionic Liquids for Green Molecular Lubrication in Nanotechnology. Tribol Lett, in press.

27. Choi SUS, Nanofluids: From Vision to Reality Through Research. J Heat TransfTrans ASME 2009;131: Art. No. 033106.

28. Fukushima T, Kosaka A, Ishimura Y, Yamamoto T, Takigawa T, Ishii N Aida T. Molecular ordering of organic molten salts triggered by single-walled carbon nanotubes. Science 2003;300:2072-2074.

29. Fukushima T, Aida T. Ionic liquids form soft functional materials with carbon nanotubes. Chem-Eur J 2007;13:5048-5058.

30. Wang J, Chu H, Li Y. Why Single-Walled Carbon Nanotubes Can Be Dispersed in Imidazolium-Based Ionic Liquids. ACS Nano 2008;2:2540-2546.

31. Fukushima T, Kosaka A, Yamamoto Y, Aimiya T, Notazawa S, Takigawa T, Inabe T, Aida T. Dramatic Effect of Dispersed Carbon Nanotubes on the Mechanical and Electroconductive Properties of Polymers Derived from Ionic Liquids. Small 2006;2,554- 560 .

32. Wang B, Wang X, Lou W, Hao J. Rheological and tribological properties of ionic liquid-based nanofluids containing functionalized multi-walled carbon nanotubes. J Phys Chem C 2010;114:8749-8754.

33. Yu B, Liu Z, Zhou F, Liu W, Liang Y. A novel lubricant additive based on carbon nanotubes for ionic liquids. Mater Lett 2008;62:2967-2969.

34. Sanes J, Carrión FJ, Bemúdez MD, Martínez-Nicolás G. Ionic liquids as lubricants of polystyrene and polyamide 6-steel contacts. Preparation and properties of new polymer-ionic liquid dispersions. Tribol Lett 2006;21:121-133.

35. Sanes J, Carrión FJ, Jiménez AE, Bermúdez MD. Influence of temperature on PA 6-steel contacts in the presence of an ionic liquid lubricant.Wear 2007;263: 658-662. 
36. Sanes J, Carrión-Vilches FJ, Bermúdez MD. E-Polym. 2007;Art. No. 005.

37. Arribas A, Bermúdez MD, Brostow W, Carrión-Vilches FJ, Olea-Mejía O. New epoxy-ionic liquid dispersions. Room temperatureionic liquid as lubricant of epoxy resin-stainless steel contacts. Express Polym Lett 2009;3:621-629.

38. Carrión FJ, Sanes J, Bermúdez MD. Effect of ionic liquid on the structure and tribological properties of polycarbonate-zinc oxide nanodispersion. Mater Lett 2007;61: $4531-4535$.

39. Bermúdez MD, Brostow W, Carrión-Vilches FJ, Sanes J. Scratch Resistance of Polycarbonate Containing ZnO Nanoparticles: Effects of Sliding Direction. J. Nanosci. Nanotechnol. 2010; 10:6683-6689.

40. Sanes J, Carrión FJ, Bermúdez MD. Effect of the addition of room temperature ionic liquid and $\mathrm{ZnO}$ nanoparticles on the wear and scratch resistance of epoxy resin. Wear 2010;268:1295-1302.

41. Arribas A, Bermúdez MD, Carrión FJ, Espejo C. Proccedings of IBERTRIB 2009.

V Iberian Tribology Conference. A. Ramalho, A. Cavaleiro, eds. Coimbra, Portugal, 2009.

42. Tan P, Zhang SL, Yue KT, Huang FJ. Comparative Raman Study of Carbon Nanotubes Prepared by D.C. Arc Discharge and Catalytic Methods. Raman Spectr. $1997 ; 28: 369-372$. 
Table 1. Thermal properties of polymers and nanocomposites

\begin{tabular}{lcc}
\hline Material & $\mathbf{T g}\left({ }^{\mathbf{}} \mathbf{C}\right)$ & $\begin{array}{c}\mathbf{T}_{\mathbf{d}}\left({ }^{\mathbf{0}} \mathbf{C}\right) \\
\text { weight loss })\end{array}$ \\
\hline PS & & 422.3 \\
\hline PS+CNT & 105.7 & 426.6 \\
\hline PS+mCNT & 105.5 & 426.4 \\
\hline PMMA & 103.0 & 374.0 \\
\hline PMMA+CNT & 104.7 & 369.0 \\
\hline PMMA+mCNT & 108.4 & 371.8 \\
\hline PC & 148.4 & 509.3 \\
\hline PC+CNT & 146.6 & 503.8 \\
\hline PC+mCNT & 145.1 & 482.3 \\
\hline
\end{tabular}


Table 2. Raman spectroscopy data

\begin{tabular}{cccc}
\hline Material & \multicolumn{2}{c}{ Raman shift } & D/G \\
& $\begin{array}{c}\text { D band }\left(\mathbf{c m}^{-1}\right) \\
\left(\mathbf{c m}^{-1}\right)\end{array}$ & G band & intensity ratio \\
\hline CNT & 1299.0 & 1579.6 & 0.74 \\
\hline mCNT & 1298.8 & 1577.8 & 0.69 \\
\hline PS+mCNT & 1310.9 & 1590.4 & 0.62 \\
\hline PMMA+mCNT & 1309.2 & 1589.0 & 0.64 \\
\hline PC+mCNT & 1308.7 & 1591.6 & 0.62 \\
\hline
\end{tabular}


Table 3. Pin-on-disc dry friction coefficients of polymers and nanocomposites

\begin{tabular}{cc}
\hline Material & $\begin{array}{c}\text { Friction } \\
\text { coefficient } \\
\text { (Standard } \\
\text { deviation) }\end{array}$ \\
\hline PS & $1.06(0.035)$ \\
\hline PS+1\%CNT & $0.89(0.089)$ \\
\hline PS+1\% mCNT & $0.86(0.042)$ \\
\hline PMMA & $0.10(0.013)$ \\
\hline PMMA+1\%CNT & $0.88(0.071)$ \\
\hline PMMA+1\%mCNT & $1.04(0.013)$ \\
\hline PC & $1.19(0.036)$ \\
\hline PC+1\%CNT & $1.17(0.082)$ \\
\hline PC+1\%mCNT & $1.15(0.015)$ \\
\hline
\end{tabular}



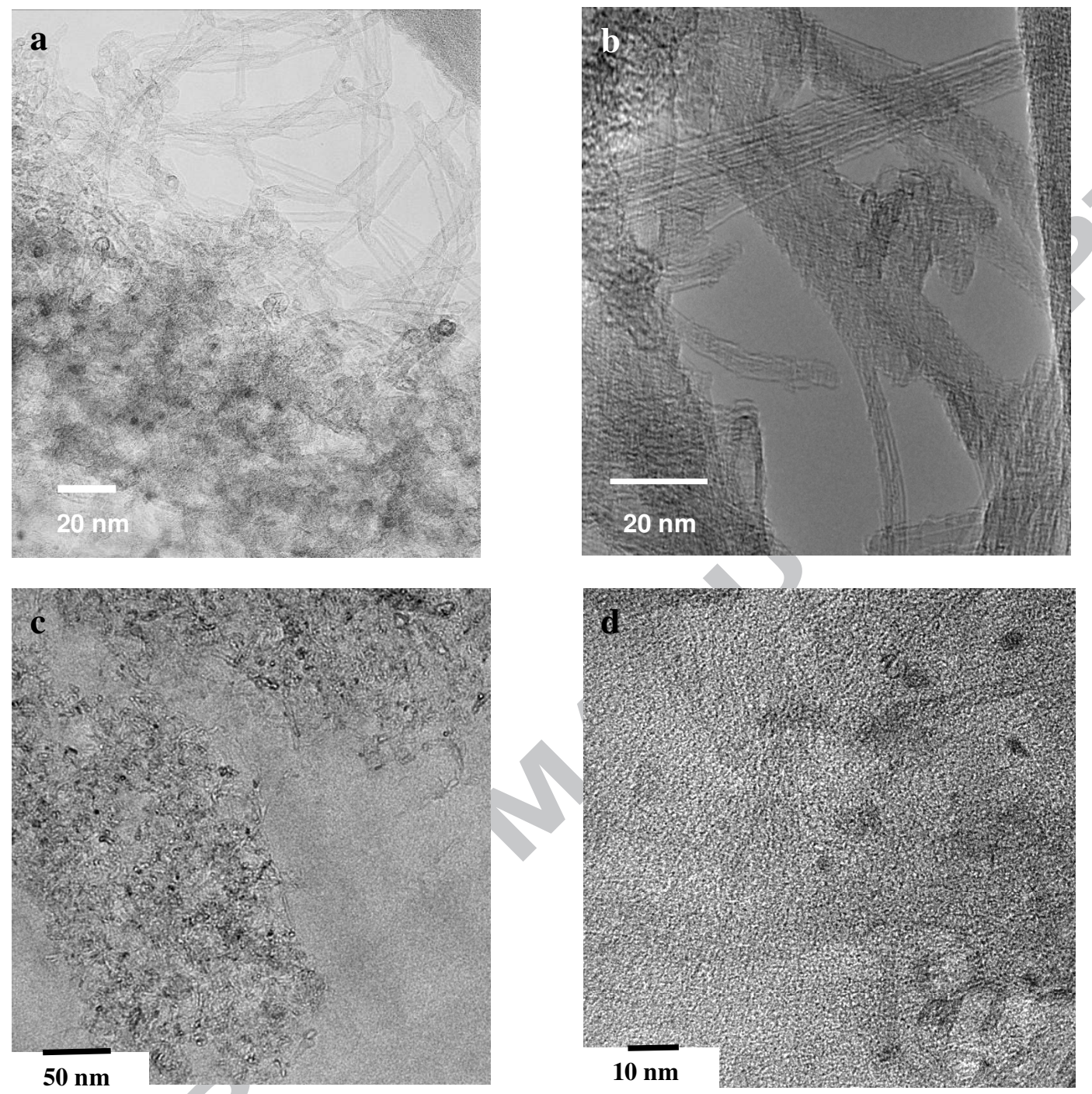

Figure 1. TEM micrographs: a) CNT; b) mCNT; c) PS+mCNT; d)PMMA+mCNT 


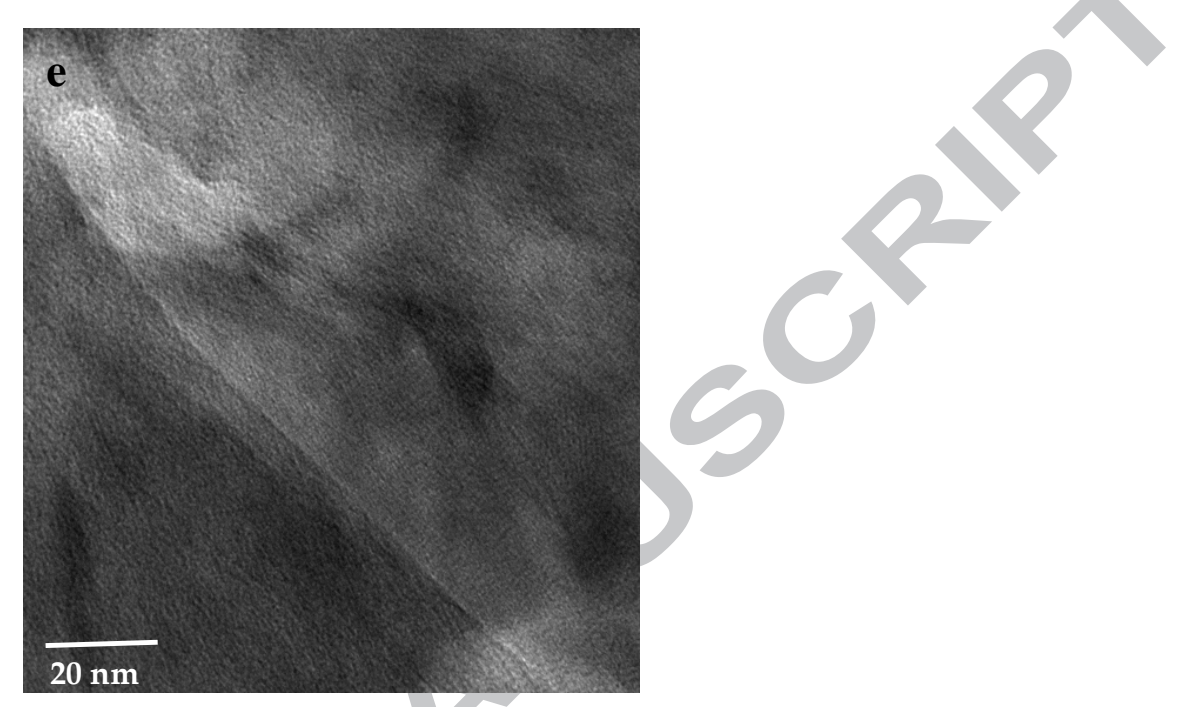

Figure 1. TEM micrographs: e) PC+mCNT 
a)

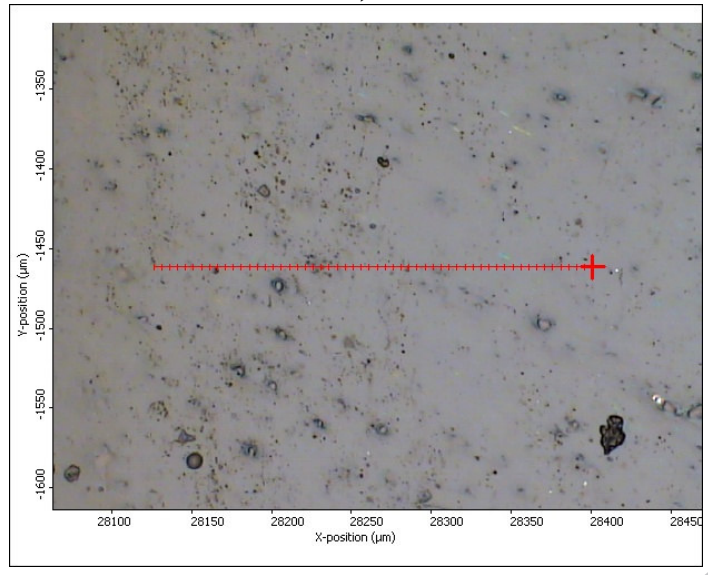

b)

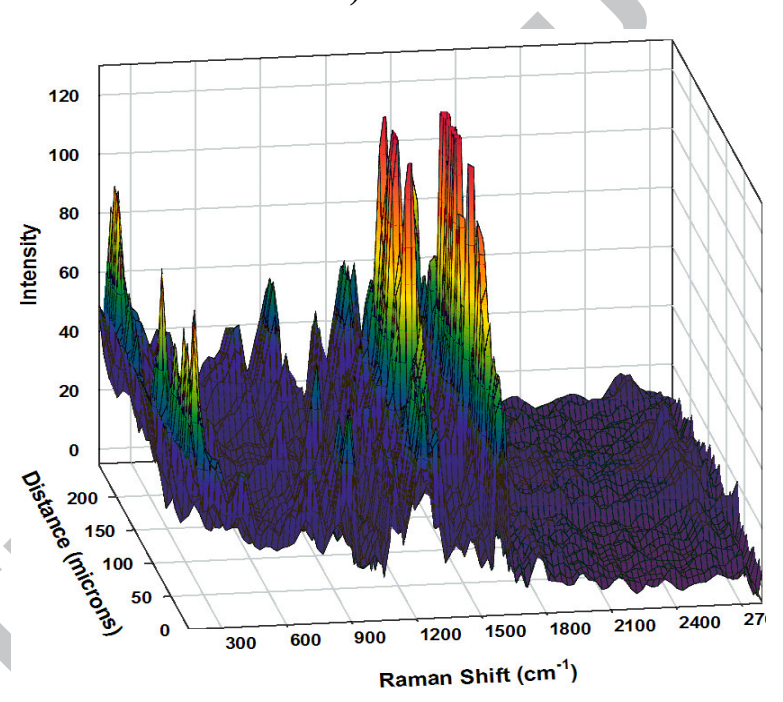

c)

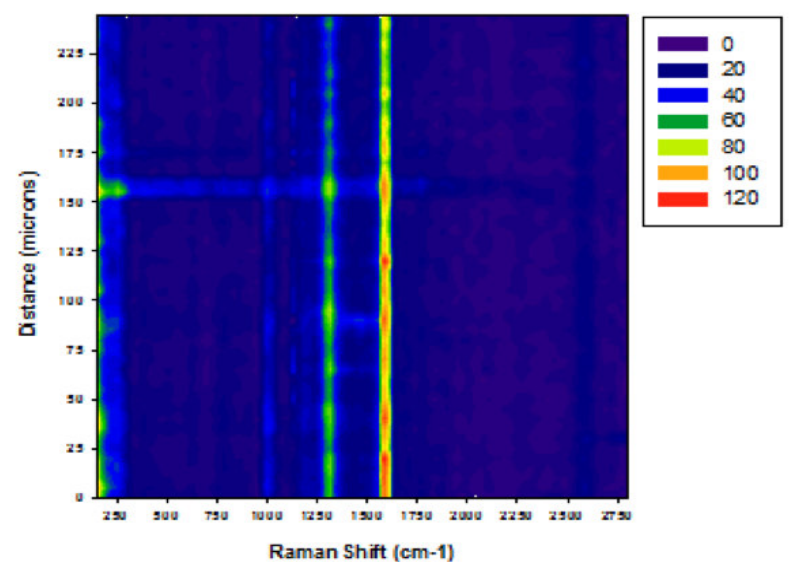

Figure 2. a) Cross section of PS+mCNT showing the scan-line; b) Scan-line Raman spectra on PS+mCNT; c) D and G band intensities along the line shown in a). 
a)

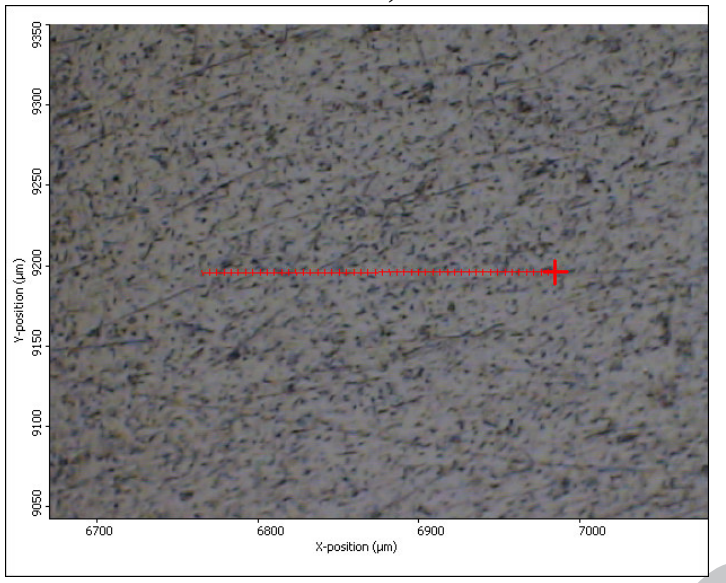

b)

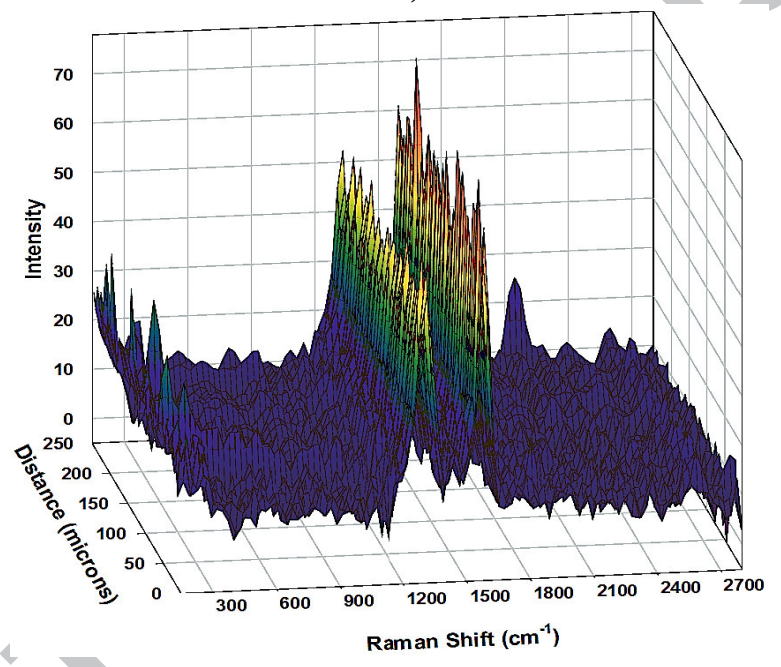

c)

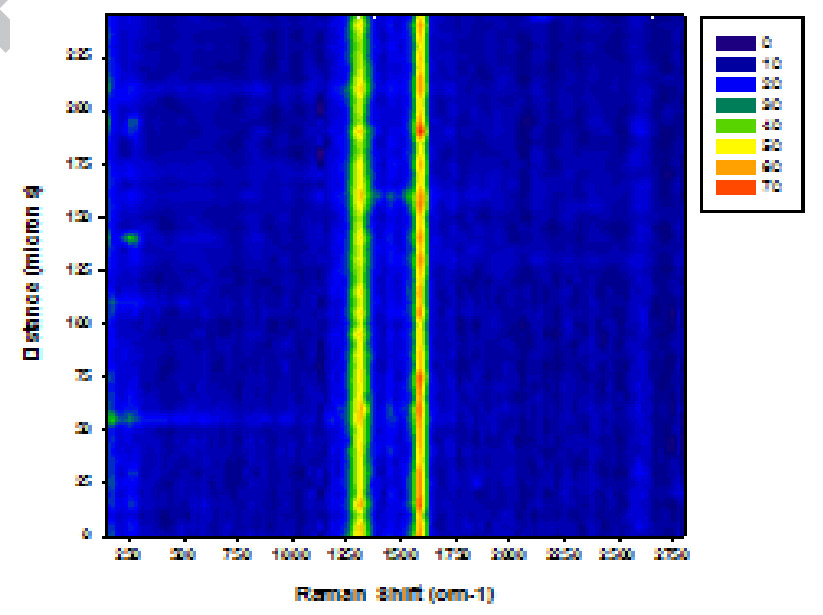

Figure 3. a) Cross section of PMMA+mCNT showing the scan-line; b) Scan-line

Raman spectra; c) D and $G$ band intensities along the line shown in a). 
a)

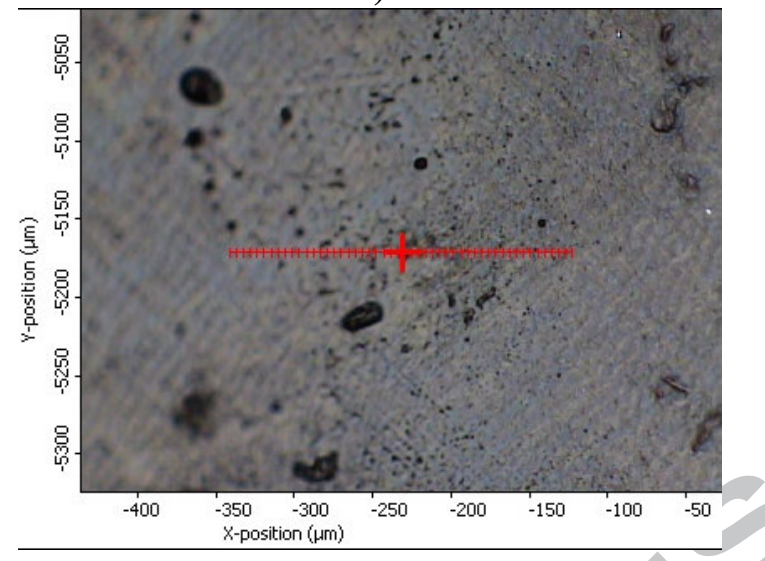

b)

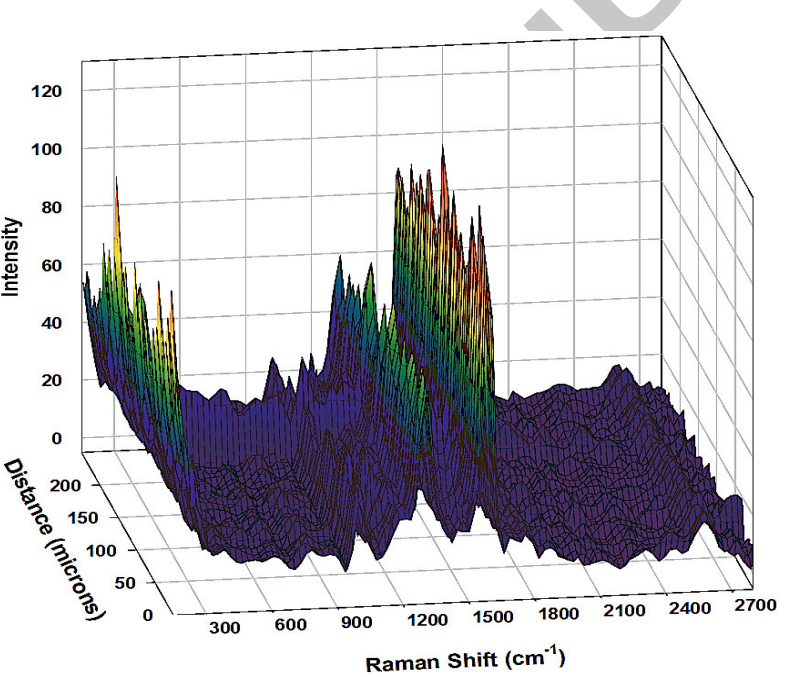

c)

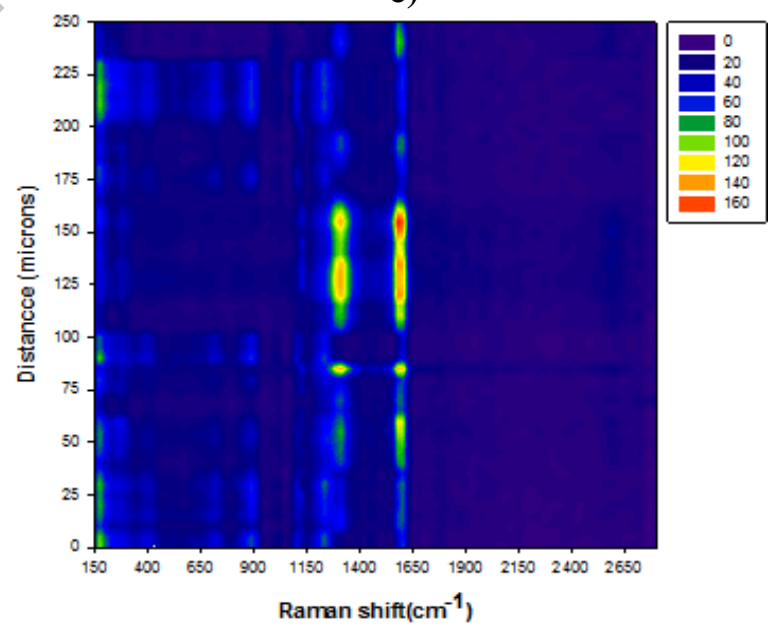


Figure 4. a) Cross section of PC+mCNT showing the scan-line; b) Scan-line Raman spectra; c) D and $G$ band intensities along the line shown in a).

a)

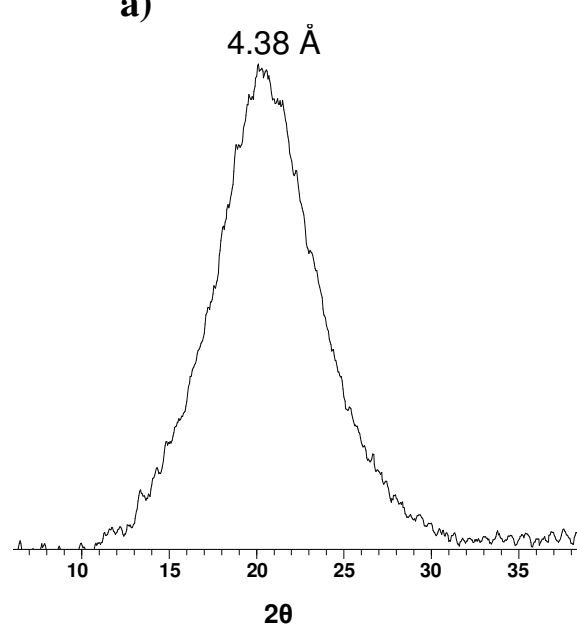

b)

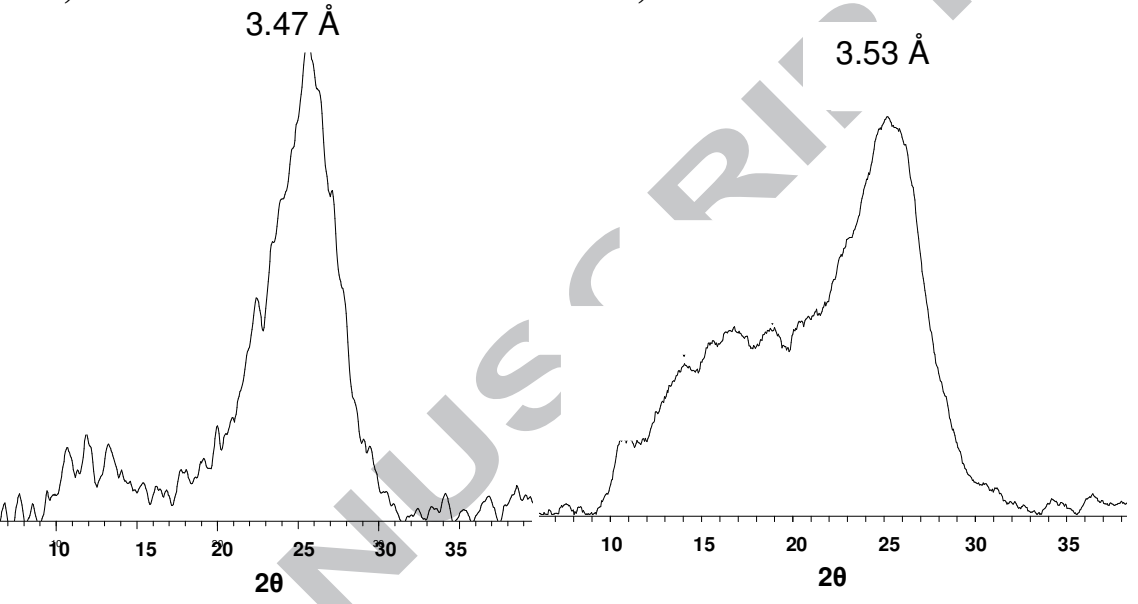

Figure 5. X-ray diffractograms: a) $[\mathrm{OMIM}] \mathrm{BF}_{4}$; b) $\mathrm{CN}$, ; c) mCNT

a)

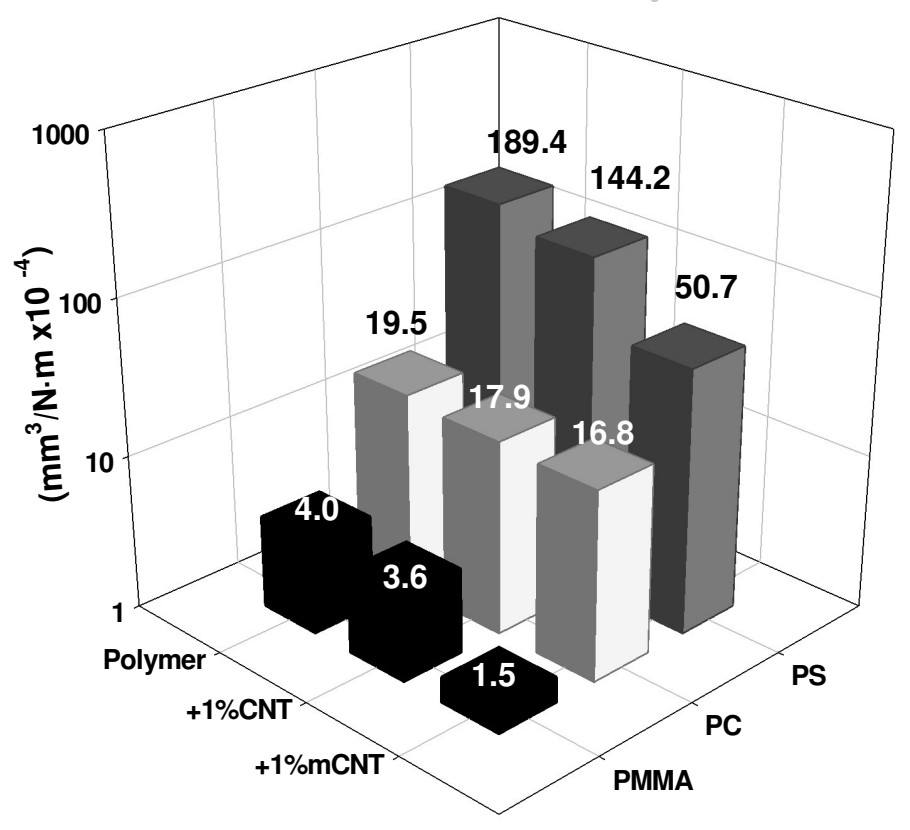

b)

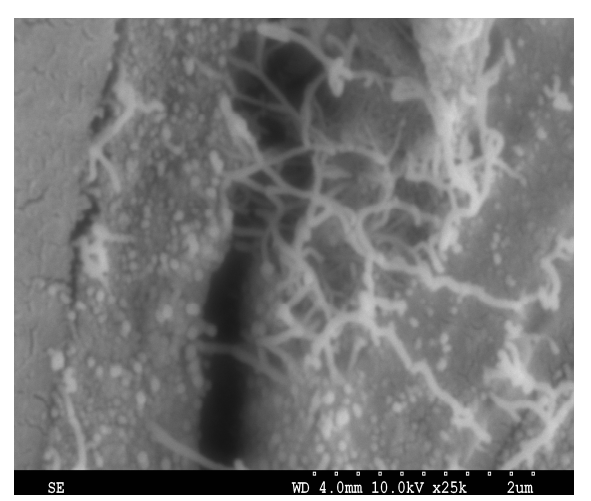

Figure 6. a) Dry specific wear rates for polymers and nanocomposites; b) SEM micrograph of the fracture surface of PS+mCNT 
a)

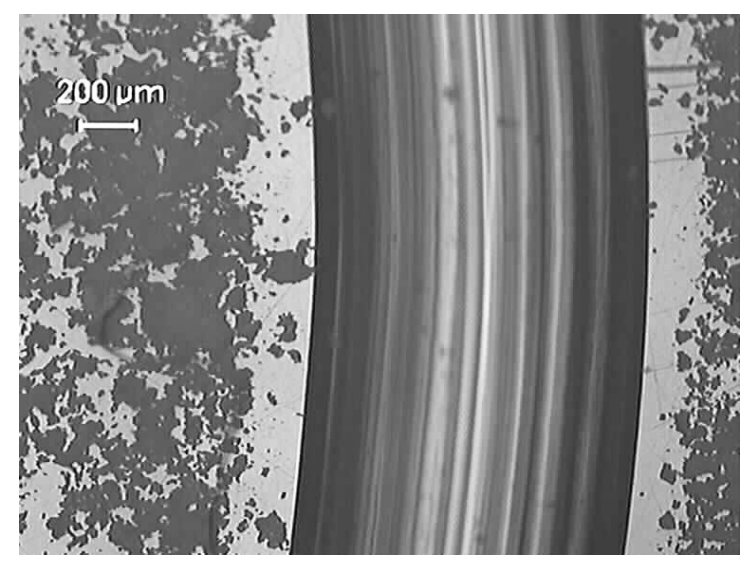

c)

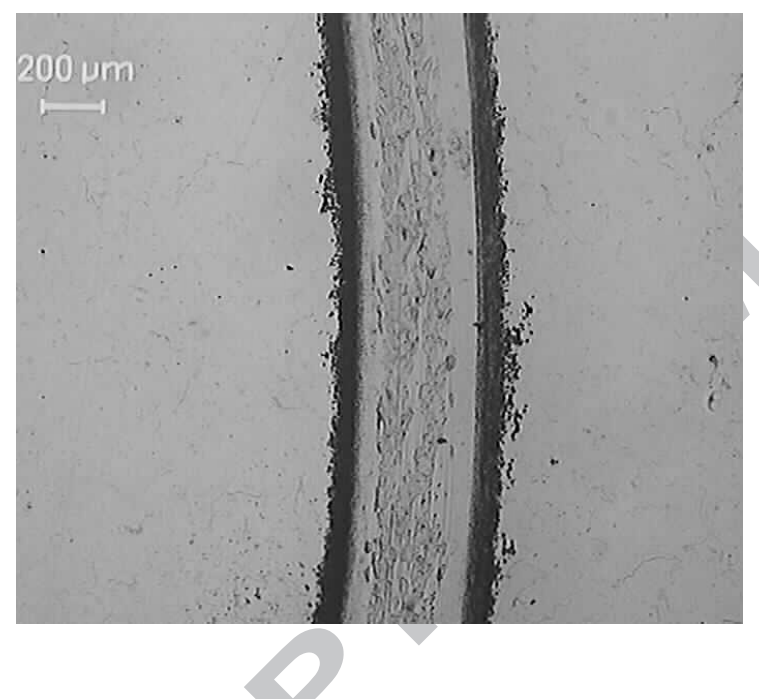

b)

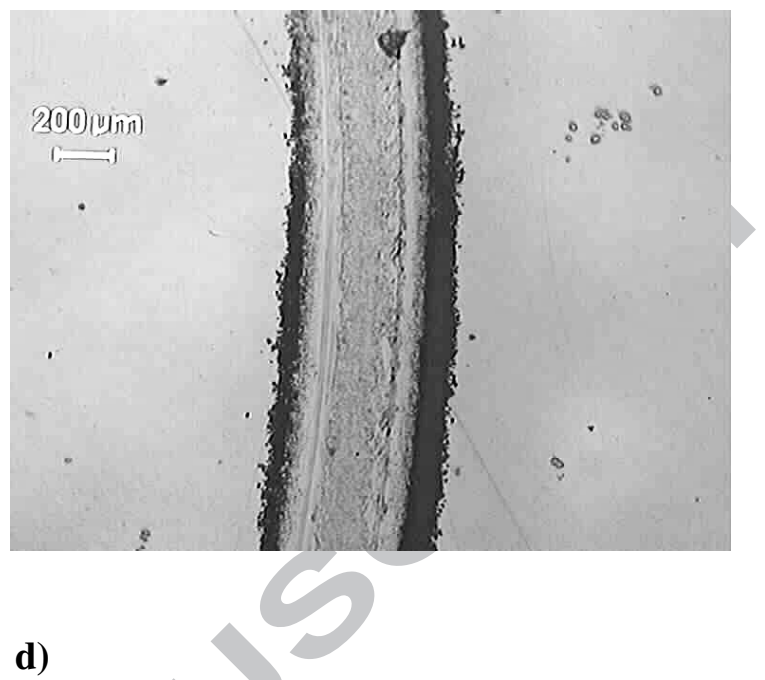

d)

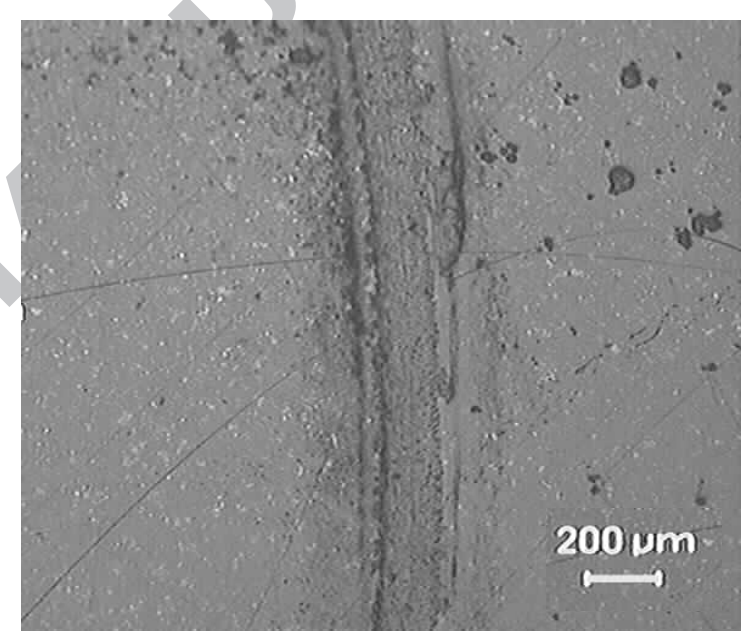

f)

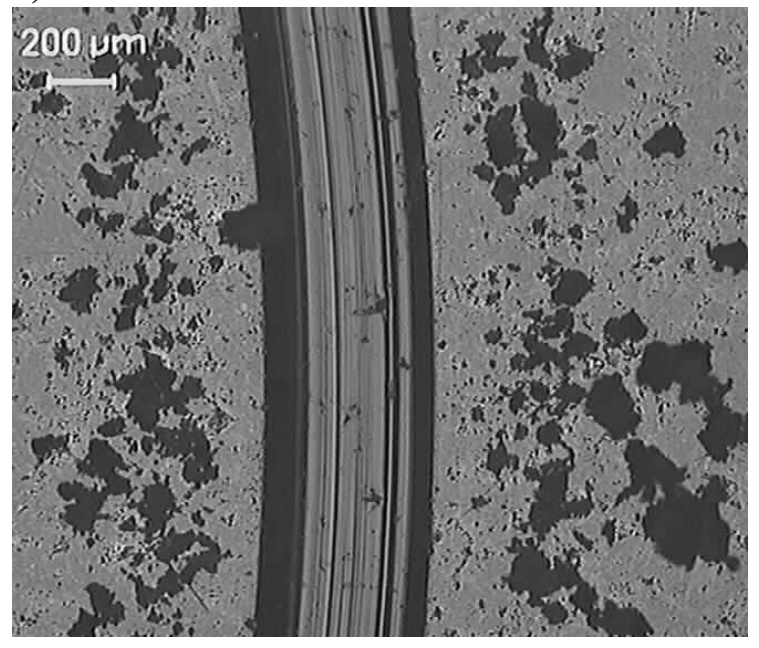


Figure 7. Optical micrographs of the wear tracks after dry pin-on-disc tests:

a) PS; b) PS+mCNT; c) PMMA; d) PMMA+mCNT; e) PC; f) PC+mCNT 